University of Wollongong

Research Online

Australian Institute for Innovative Materials -

Papers

Australian Institute for Innovative Materials

$1-1-2014$

\title{
Capacitive behavior of latex/single-wall carbon nanotube stretchable electrodes
}

Hyeon Taek Jeong

University of Wollongong, hj632@uowmail.edu.au

Byung Kim

University of Wollongong, bkim@uow.edu.au

Robert Gorkin III

University of Wollongong, rgorkin@uow.edu.au

Michael J. Higgins

University of Wollongong, mhiggins@uow.edu.au

Gordon G. Wallace

University of Wollongong, gwallace@uow.edu.au

Follow this and additional works at: https://ro.uow.edu.au/aiimpapers

Part of the Engineering Commons, and the Physical Sciences and Mathematics Commons

Research Online is the open access institutional repository for the University of Wollongong. For further information contact the UOW Library: research-pubs@uow.edu.au 


\title{
Capacitive behavior of latex/single-wall carbon nanotube stretchable electrodes
}

\begin{abstract}
In this report single-wall carbon nanotubes (SWNTs) were coated onto latex using spray coating to produce a stretchable electrode. The electrochemical properties of the electrode were determined using cyclic voltammetry and electrochemical impedance spectroscopy and galvanostatic charge/discharge tests were also carried out. The impedance and charge/discharge curves of the latex/SWNTs electrode showed good capacitive behavior even after repetitive stretching to $100 \%$ strain. The highest capacitance value obtained for the unstretched SWNTs electrode was $119 \mathrm{~F} \mathrm{~g}-1$ in $1 \mathrm{M} \mathrm{Na} 2 \mathrm{SO} 4$ at $5 \mathrm{mV} \mathrm{s}-1$. After the 100 th stretch $\approx 80 \%$ of the original capacitance value was retained.
\end{abstract}

\section{Keywords}

behavior, stretchable, single, capacitive, wall, nanotube, carbon, latex, electrodes

Disciplines

Engineering | Physical Sciences and Mathematics

\section{Publication Details}

Jeong, H. Taek., Kim, B. Chul., Gorkin, R., Higgins, M. J. \& Wallace, G. G. (2014). Capacitive behavior of latex/single-wall carbon nanotube stretchable electrodes. Electrochimica Acta, 137 372-380. 


\title{
Capacitive behavior of latex/single-wall carbon nanotube
}

\section{stretchable electrodes}

Hyeon Taek Jeong ${ }^{1}$, Byung Chul Kim ${ }^{2}$, Robert Gorkin ${ }^{1}$, Michael J. Higgins ${ }^{1}$ and Gordon G. Wallace ${ }^{1}$ *

\begin{abstract}
${ }^{1}$ ARC Centre of Excellence for Electromaterials Science, Intelligent Polymer Research Institute, AIIM Facility, Innovation Campus, University of Wollongong, Wollongong, NSW 2522, Australia.
\end{abstract}

${ }^{2}$ Department of Chemistry, Dongguk University

Pil-dong 3-ga, Jung-gu, Seoul, 100-715, South Korea.

\section{Author for correspondence:}

Professor Gordon G. Wallace

ARC Centre of Excellence for Electromaterials Science|Intelligent Polymer Research Institute AIIM Facility, Innovation Campus

University of Wollongong

Wollongong NSW Australia 2522

Tel: +61 242981439

gwallace@uow.edu.au 


\begin{abstract}
In this report single-wall carbon nanotubes (SWNTs) were coated onto latex using spray coating to produce a stretchable electrode. The electrochemical properties of the electrode were determined using cyclic voltammetry and electrochemical impedance spectroscopy and galvanostatic charge/discharge tests were also carried out. The impedance and charge/discharge curves of the latex/SWNTs electrode showed good capacitive behavior even after repetitive stretching to $100 \%$ strain. The highest capacitance value obtained for the unstretched SWNTs electrode was $119 \mathrm{~F} \mathrm{~g}^{-1}$ in $1 \mathrm{M} \mathrm{Na}_{2} \mathrm{SO}_{4}$ at $5 \mathrm{mV} \mathrm{s}^{-1}$. After the $100^{\text {th }}$ stretch $\approx 80 \%$ of the original capacitance value was retained.
\end{abstract}

Keywords: stretchable capacitor, energy storage, spray coating technique, single-wall carbon nanotubes 


\section{Introduction}

The development of novel energy storage devices is of great significance for applications in wearable electronics [1-3]. Amongst the diverse range of energy storage devices available, electrochemical capacitors (ECs) are promising candidates due to their high power density, long life, durability and safety. Such characteristics are desirable for various applications, including high performance sportswear, wearable displays and embedded health monitoring devices [4, 5]. Developing technologies such as foldable displays [6], functional electronic eyes [7], transistors [8] and photovoltaic devices [9] also require the continued development of stretchable electrodes. These applications demand power systems with high capacitance but also require the material to be highly flexible and stretchable $[10,11]$. Two types of ECs, which store charge by electrochemical means, have been developed. The first is the electrochemical double layer capacitor (EDLC) which, instead of having two plates separated by a thick insulator, is based on the operating principle of an electrical double layer that is formed at the interface between an electrode and electrolyte [1, 4]. The second type is based on Faradaic pseudo-capacitance where charge is transferred at the surface or in the bulk near the surface of the solid electrode materials $[3,5]$.

Various materials have been used as substrates for stretchable conductors. These include silicone rubber, poly (dimethylsiloxane) (PDMS), nitrile-butadiene rubber (NBR), natural-latex rubber, polyurethane and cotton [12-17]. Among the polymers available, latex rubber is widely available, inexpensive, non-toxic, eco-friendly, highly stretchable and easily processed. Most work to date using latex has focused on sensors and actuators. Sommerdijk et al have developed a biosensor based on a polypyrrole/latex composite [18], while Kim et al have reported a micro-actuator using latex rubber as a membrane [19]. To our knowledge there have been no studies for the capacitive behavior of SWNTs coated onto latex rubber as a stretchable substrate. 
Single-wall carbon nanotubes (SWNTs) are highly suitable for preparation of high performance electrochemical supercapacitors due to their high electrical conductivity, thermal and chemical stability and large surface area [20]. In addition, SWNTs possess high flexibility, low mass density and large aspect ratio (typically >1000), enabling them to maintain conductive pathways by bridging cracked regions under large strain [21-23]. However, a major problem of pristine SWNTs is aggregation due to van der Waals force, which results in poor dispersability of pristine SWNTs in most solvents. In order to overcome this issue, acid treatment has been used to improve dispersability and capacitance values of SWNTs in fabricating supercapacitors [24]. Acid treatment using strong acids, including nitric and sulfuric acid, can introduce oxygen containing functional groups such as carboxylic (-COOH) and hydroxyl $(-\mathrm{OH})$ groups on the surface of SWNTs. -COOH groups on SWNTs can enhance surface wettability of SWNTs to improve ionic conductivity between the electroelectrolyte interface. These functional groups also offer more available sites to enable physisorption of free electrolyte ions. Previous reports have indicated that nitric acid treatment can significantly improve capacitance values of the carbon nanotube based capacitors $[25,26]$.

Initial studies of electrochemical capacitors with SWNTs electrodes [27, 28] reported significant increases in electrochemical performance [29-33]. Lee et al. [34] have reported supercapacitors fabricated from SWNTs grown by arc discharge and mixed with poly(vinylidenechloride) as a binder and then dissolved in tetrahydrofuran. They obtained a maximum specific capacitance of $180 \mathrm{~F} \mathrm{~g}^{-1}$ and power density of $20 \mathrm{KW} \mathrm{kg}^{-1}$ at an energy density of $6.5 \mathrm{Wh} \mathrm{kg}^{-1}$ in $7.5 \mathrm{~N}$ potassium hydroxide (KOH) electrolyte. Pushparaj et al. [2] used nanoporous cellulose composite paper embedded with aligned multi-wall carbon nanotubes (MWNTs) electrodes to achieve an energy density of $13 \mathrm{Wh} \mathrm{kg}^{-1}$ with specific capacitance of $36 \mathrm{~F} \mathrm{~g}^{-1}$ and power density of $1.5 \mathrm{Wh} \mathrm{kg}^{-1}$. Yu et al. [11] have reported a 
stretchable supercapacitor based on buckled SWNTs macro-films on poly(dimethylsiloxane) that has a maximum specific capacitance of $54 \mathrm{~F} \mathrm{~g}^{-1}$ and power density of $0.5 \mathrm{KW} \mathrm{kg}^{-1}$ at 4.2 Wh $\mathrm{kg}^{-1}$ energy density. The buckled SWNTs films could stretch up to $30 \%$ strain.

Established methods for the preparation of carbon nanotube films include vacuum filtration [35, 36], dip coating [37, 38], ink-jet printing [39] and electro spray deposition [40]. Even though the vacuum filtration method has been widely used to fabricate CNTs films (bucky paper), this method presents practical challenges for scale up of industrial applications and is limited to deposition on porous substrates [38]. Dip and spin coating methods allow the preparation of CNTs films on various substrates at the laboratory scale, but are time consuming when thicker films are required and limited by lack of control of film quality over large areas [35].

In this work, we report on the preparation of a flexible and stretchable electrode using a simple and inexpensive spray coating technique, which is potentially applicable at an industrial scale. Functionalized (carboxylated) single-wall carbon nanotubes (SWNTs) were sprayed onto gold coated latex to create an electrode that displays practically useful electronic properties even after repeated stretching to $100 \%$ strain. This is demonstrated through characterization of their electrochemical properties such as changes in specific capacitance under varying mechanical stress and strain. We also describe the surface morphology of SWNTs films on the latex substrate with respect to the capacitance of the stretchable electrode. 


\section{Experimental}

\subsection{Materials}

Single-wall carbon nanotubes (SWNTs) were purchased from Carbon Nanotechnologies, Inc (Houston, TX). N, N-Dimethylformamide (AR grade), concentrated nitric acid (70\%) and sodium sulfate (AR grade) were obtained from Sigma-Aldrich and used as received. The liquid latex was purchased from AA Rubber and Seals. Pty, Ltd (Belmore, NSW, Australia).

\subsection{Purification and functionalization of SWNTs}

Metallic oxides were removed from pristine SWNTs by nitric acid treatment. Approximately $200 \mathrm{mg}$ of SWNTs were refluxed in $40 \mathrm{~mL} 5 \mathrm{M}$ nitric acid for 6 hours, then filtered through a polytetrafluoroethylene-coated polypropylene filter $(0.2 \mu \mathrm{m})$ and rinsed with deionized water. The sample was freeze dried for 2 days [41].

\subsection{Preparation of SWNTs coated stretchable electrode}

\subsubsection{Au modified latex film}

A suitable amount of natural liquid latex (with ammonia to prevent bacteria spoilage) was poured into a glass mold $(30 \mathrm{~cm} \times 5 \mathrm{~cm} \times 1 \mathrm{~mm})$ and then allowed to dry at room temperature for 24 hrs. To fabricate the electrode, a section of the latex film $(1 \mathrm{~cm} \mathrm{x} 5 \mathrm{~cm} \times 1 \mathrm{~mm})$ was transferred to a glass microscope slide, stretched to introduce a 100\% uniaxial pre-strain and then held under tension using double-sided adhesive tape. After stretching, a $150 \mathrm{~nm}$ thick layer of gold was coated onto the dried latex film by sputter coating (Edwards Sputter Coater AUTO306, BOC Ltd, United Kingdom), allowing it to be used as a current collector. 


\subsubsection{Carbon nanotube dispersion}

Acid treated SWNTs (5mg) were mixed with 10mL DMF, then ultrasonicated (Sonics Vibracell ultrasonic processor, 500 watt, 30\% amplitude, USA) for 1 hr to create a stable dispersion.

\section{Characterization}

3.1 Physical and chemical characteristics of the pristine and functionalized (acid-treated) SWNTs

\subsubsection{FT-IR spectroscopy}

The FT-IR spectra of pristine and functionalized SWNTs samples were measured using a Shimadzu IR Prestige-21 FTIR spectrophotometer with single reflection HATR accessories (Miracle, Pike Technologies). The scanning range of the experiment was $1000-4000 \mathrm{~cm}^{-1}$ on transmittance mode with 30 scans and 8.0 resolutions.

\subsubsection{Raman spectroscopy}

Raman analysis was carried out using a JY-HR800 Raman spectrometer equipped with a visible Raman microscope and Olympus BX41 and CCD detector. The excitation wavelength was $632.81 \mathrm{~nm}$ and spectra were obtained over $30 \mathrm{~s}$ at $1.0 \mathrm{~cm}^{-1}$ resolution.

\subsubsection{Morphology measurement of the latex/SWNTs film}

Scanning electron microscopy (SEM) images of SWNTs (pristine and functionalized SWNTs on silicon wafer) and SWNTs film on the latex substrate were obtained using a JEOL JSM7500FA field emission SEM. The accelerating voltage was $5.0 \mathrm{kV}$ and the emission current was $10 \mu \mathrm{A}$. 


\subsubsection{Electrical conductivity measurement}

The electrical conductivity measurement of the SWNTs film on the latex was carried out by a JANDEL Four-Point Probe conductometer (Jandel Engineering Ltd, UK). The electrical resistivity could be expressed as [42];

$$
\rho=K(\mathrm{~V} / \mathrm{I}) * t \quad \text { Eq. }(1)
$$

Where, $\rho$ is the electrical resistivity of the SWNTs film, $K$ is a geometric factor $(K=4.5324)$, $\mathrm{V}$ is the electric potential across the two inner probes, $\mathrm{I}$ is the applied current and $\mathrm{t}$ is the thickness of the SWNTs film (cm). The electrical conductivity of the SWNTs film is calculated by the following equation;

$$
\sigma=1 / \rho \text { Eq. (2) }
$$

\subsection{Electrochemical properties of the latex/SWNTs electrode}

\subsubsection{Cyclic Voltammetry}

Cyclic Voltammetry (CV) measurements of the latex/SWNTs electrodes were performed at room temperature with a three electrode system using an electrochemical analyzer (EDAQ Australia) and EChem V2 software (ADI Instruments Pty. Ltd). In all cases, the latex/SWNTs electrode was used as the working electrode with $\mathrm{Ag} / \mathrm{AgCl}(3 \mathrm{M} \mathrm{NaCl})$ aqueous solution as the reference electrode and Pt mesh as a counter electrode. All of the CV measurements were recorded in $1 \mathrm{M} \mathrm{Na}_{2} \mathrm{SO}_{4}(\mathrm{aq})$ under 0 to $100 \%$ strain and after 50 and 100 stretches (at $100 \%$ strain) over the scan rate range of $5-500 \mathrm{mV} \mathrm{s}^{-1}$. All of the electrodes $(\mathrm{n}=10)$ had stretch and release cycles applied at a speed of $2 \% \mathrm{~s}^{-1}$ for 50 and 100 stretches using a Shimadzu EZ mechanical tester. 


\subsubsection{Electrochemical impedance}

Electrochemical impedance spectroscopy (EIS) was used to probe the electrical double layer effects at the electrode/electrolyte interface. EIS measurements were performed at room temperature using a Gamry EIS $3000^{\mathrm{TM}}$ system (Gamry, USA) where the frequency range spanned $100 \mathrm{kHz}$ to $0.01 \mathrm{~Hz}$ with an amplitude of $10 \mathrm{mV}$ (rms) at open circuit potential.

\subsubsection{Charge and discharge measurement}

A pair of latex/SWNTs film electrodes was set up in a glass beaker for use as the anode and cathode. The constant current charge-discharge measurement was carried out at $0.25 \mathrm{~mA} / \mathrm{cm}^{2}$ in the voltage range between 0.1 and $1 \mathrm{~V}$ in $1 \mathrm{M}$ aqueous $\mathrm{Na}_{2} \mathrm{SO}_{4}$ electrolyte.

\section{Results and Discussion:}

Figure 1 presents SEM micrographs and FT-IR of pristine and functionalized (acidtreated) single-wall carbon nanotubes (SWNTs). The pristine SWNTs are bundled with an average diameter in excess of $100 \mathrm{~nm}$ before functionalization (Fig. 1a), while the functionalized SWNTs have average bundled diameters of approximately 10nm (Fig. 1b). Importantly, the pristine SWNTs in the DMF (Fig. 1a see inset photo) were sediment at the bottom of the vial within $1 \mathrm{hr}$, while the functionalized SWNTs show good dispersion for up to 60 days (Fig. 1b see inset photo). This indicates that the functional groups on the SWNTs can significantly improve dispersability and wettability of the SWNTs in the DMF. It also implies that the $\pi$ - $\pi$ interaction and van der Waals force between the nanotubes decreases with functionalization of the SWNTs [43].

The presence of functional groups on the SWNTs is confirmed by FT-IR spectroscopy (Fig. 1c and d). The carbonyl group stretch of the carboxylate anions appears at $1581 \mathrm{~cm}^{-1}$ for the acid treated SWNTs (Fig. 1d). The peaks at $1736 \mathrm{~cm}^{-1}$ and $3428 \mathrm{~cm}^{-1}$, which are from the 
$\mathrm{O}-\mathrm{HCO}$ stretch of the carboxylic acid groups, indicates that the functional group on the SWNTs is successfully introduced by acid treatment (Fig. 1d) [24, 44]. In contrast, the same peaks are not observed for the pristine SWNTs (Fig. 1c).

Raman spectroscopy in the high frequency range between 1500 and $1600 \mathrm{~cm}^{-1}$ gives the intensity of the G-band that relates to the arrangement of hexagonal lattices of graphite (Fig. 2). The other peak at $1200-1400 \mathrm{~cm}^{-1}$ or D-band indicates the level of defect or disorder. In the low-frequency range $\left(100-375 \mathrm{~cm}^{-1}\right)$, the measurement of the radial breathing mode (RBM) is a useful way of analyzing the SWNTs diameter distribution. By comparing pristine SWNTs with acid-treated SWNTs, the ID/IG ratio of pristine SWNTs is smaller than that of the acid-treated SWNTs (Fig. 2, see table). This indicates that the pristine SWNTs have less defects on the carbon structure when compared to the functionalized SWNTs $[45,46]$. The relation $\omega=248 / d$ is used to determine the approximate diameter of SWNTs, where $\omega$ is the RBM frequency in $\mathrm{cm}^{-1}$ and $d$ is the diameter of the SWNTs [47-49]. According to the above equation, the diameter of the pristine SWNTs is in the range of $1-1.17 \mathrm{~nm}$ and the diameter distribution of the functionalized SWNTs is in the range of 1-1.15 nm. This implies that acidtreatment does not significantly modify the diameter of the SWNTs. In addition, D and G band peaks for functionalized SWNTs are slightly shifted right from that of pristine SWNTs (Fig. 2, see table), which may be due to the presence of functional groups on the SWNTs [50].

Figure 3 illustrates the procedure used to prepare the stretchable latex/SWNTs electrode via spray coating. The latex film $(1 \mathrm{~cm} \times 5 \mathrm{~cm} \times 1 \mathrm{~mm})$ is transferred to a glass microscope slide (step 1), stretched to introduce a 100\% uniaxial pre-strain and then held under tension using double-sided adhesive tape (step 2). $150 \mathrm{~nm}$ of gold is then coated onto the latex film as a current collector (step 3). A hotplate is covered with aluminium foil and the sample/slide assembly fixed horizontally to the centre of the foil with adhesive tape. Once the hotplate is stabilized at $80^{\circ} \mathrm{C}$, the assembly is coated with the SWNTs dispersion using a 
small airbrush (Bunnings, Australia) with a nozzle diameter of approximately $1 \mathrm{~mm}$ (step 4). An air pressure of 50 psi is applied and the liquid feed rate adjusted at the nozzle to approximately $0.15 \mathrm{~mL} / \mathrm{min}$. Spraying is performed manually at a distance of $10-15 \mathrm{~cm}$ from the latex substrate. Many thin coats are applied, allowing a few seconds for drying between coats, until the entire $10 \mathrm{~mL}$ suspension is exhausted. After spray coating, the latex/SWNTs film is dried in an oven at $120^{\circ} \mathrm{C}$ for $30 \mathrm{~min}$ to evaporate residual solvent.

Cyclic Voltammetry (CV) measurements were obtained to investigate the electrochemical properties of the latex/SWNTs films as a function of strain (Fig. 4a, b). The redox peaks can be attributed to the presence of functional groups (- $\mathrm{COOH}$ or $-\mathrm{OH})$ on the carbon nanotubes [51]. The specific capacitance is calculated on the basis of the following equation [52]:

$$
C_{s p}=\int_{E 1}^{E 2} \mathrm{i}(\mathrm{E}) d E / 2(E 2-E 1) m v \quad \text { Eq. (3) }
$$

Where $C_{s p}$ is the specific capacitance of the individual electrode, $E 1$ and $E 2$ are the cutoff potentials in $\mathrm{CV}$ measurements, $i(E)$ is the instantaneous current, E2 - E1 is the potential window width, $m$ is the mass of active material (the mass difference of the working electrode before and after spray coating), $v$ is the potential scan rate and $\int_{E 1}^{E 2} \mathrm{i}(\mathrm{E}) d E$ is the total voltammetric charge obtained by integration of the positive and negative sweep in the CV measurements. The highest specific capacitance value obtained for the unstretched SWNTs electrode is $119 \mathrm{~F} \mathrm{~g}^{-1}$ in $1 \mathrm{M} \mathrm{Na}_{2} \mathrm{SO}_{4}$ at $5 \mathrm{mV} \mathrm{s}^{-1}$. In comparison, the pristine SWNTs electrode produced a highest capacitance value of $52 \mathrm{~F} \mathrm{~g}^{-1}$ under the same conditions (see supplementary section, Fig. S1). To assess the reproducibility of the fabrication approach we assessed the specific capacitance of 10 electrodes. The average specific capacitance decreases slightly with an increase in scan rate but retain a value of $100.6 \pm 5.0$ (mean \pm S.D., $n=10$ electrodes) $\mathrm{F} \mathrm{g}^{-1}$ at $500 \mathrm{mV} \mathrm{s}^{-1}$, reflecting an energy density of $33.5 \pm 1.6$ (mean \pm S.D., $\mathrm{n}=10$ electrodes) $\mathrm{Wh} \mathrm{kg}^{-1}$ and power density of $50.3 \pm 2.4$ (mean \pm S.D., $\mathrm{n}=10$ electrodes) $\mathrm{KW} \mathrm{kg}^{-}$ 
${ }^{1}$ (See Fig. 4, table). The energy and power density of the latex electrode was calculated according to the following equation:

$$
E=\frac{1}{2} \mathrm{C}_{\mathrm{sp}} V^{2} ; P=\frac{E}{t} \quad \text { Eq. (4) }
$$

where $C_{s p}$ is the specific capacitance of the latex electrode, $V$ is the operating voltage and $t$ is the sweep time. Under fixed strain over the range (20-100\%) the capacitance values obtained at $5 \mathrm{mV} \mathrm{s}^{-1}$ decrease. The values decrease further at zero strain, though slightly increase at higher scan rates. Specific capacitance versus scan rate is plotted for the electrode under repeated stretching (Fig. 4d) and strain conditions (Fig. 4b). The specific capacitance decrease to $110 \pm 2.5$ (mean \pm S.D., $\mathrm{n}=10$ electrodes) and $96 \pm 2.4$ (mean \pm S.D., $\mathrm{n}=10$ electrodes) $\mathrm{F} \mathrm{g}^{-1}$ after 50 and 100 stretches (at 100\% strain), respectively (Fig. 4d). The performance also decreased to $48.7 \pm 4.8$ (mean \pm S.D., $\mathrm{n}=10$ electrodes) $\mathrm{F} \mathrm{g}^{-1}$ at $5 \mathrm{mVs}^{-1}$ under $100 \%$ level of strain (Fig. 4b).

SEM images of the latex/SWNTs electrodes are shown in Figure 5. The surface morphology of the relaxed SWNTs film shows a lot of islands with a very porous and welldefined periodic buckling structure before prolonged stretching (Fig. 5a and 5b). This characteristic is strongly desirable since it maximizes surface area. However, there are some cracks evident on the SWNTs film after 100 stretch cycles with applied strain of $100 \%$ (Fig. 5c and 5d). The introduction of repeated stresses and strain is likely to result in the formation of these cracks on the SWNTs films that cause a decrease in electrical conductivity of the SWNTs film and thus affect the capacitance. We also attribute these cracks to irreversible loss of junctions between SWNTs [53]. However, $\approx 80 \%$ and $40 \%$ of the initial capacitance remains after 100 stretching cycles and applied strain of 100\%, respectively (Fig. 4b and d). 
The electrical conductivities of the latex/SWNTs electrode decrease with an increasing number of stretches and strain percentage (Fig. 6). The electrical conductivity of the unstretched SWNTs film on the latex is $2.5 \times 10^{3} \mathrm{Scm}^{-1}$. However, the electrical conductivity of the SWNTs film decreases to $5.1 \mathrm{~S} / \mathrm{cm}$ and $2.35 \times 10^{2} \mathrm{~S} \mathrm{~cm}^{-1}$ after 100 stretches (Fig. 6a) and applied strain of $100 \%$ (Fig. 6b), respectively. Again, the emergence of cracks (Fig. 5c and 5d) on the SWNTs film after 100 stretches with applied strain of $100 \%$ is the most likely cause of the decrease in conductivity. We believe that the resistivity under strain is dominated by the SWNTs with only minor contributions from the current collector (gold film). This is based on our observations of surface resistance measurements (using a 4-point-probe) performed on both the SWNT and gold films after stretching cycles of the latex. For instance, the surface resistance of the gold current collector on the unstretched latex is $2.8 \Omega / \mathrm{sq}$, which increases to $6.8 \Omega /$ sq after 200 stretching cycles (see supplementary section, Fig. S2). In contrast, the surface resistance of the SWNTs film on the gold coated latex increases from an initial value of $10 \Omega$ /sq (unstretched) to $106 \Omega$ /sq when placed under $100 \%$ strain. A further increase in resistance to $4.9 \mathrm{~K} \Omega / \mathrm{sq}$ occurs after 100 stretching cycles, thus indicating a significant increase in resistance due to cracking of the SWNTs.

Nyquist plots obtained from impedance measurements show characteristic capacitive behavior of SWNTs (Fig. 7) [54]. In the high frequency domain for stretching (inset Fig. 7a) and applied strain (inset Fig. 7b), there are smaller semi-circles attributed to minimization of the contact impedance between the SWNTs film and current collector as well as electrolyte resistance within the pores of the SWNTs film [55]. In the middle frequency regime, a small $45^{\circ}$ degree inclination is seen for the latex/SWNTs electrodes. This arises as a result of distribution capacitance/impedance in a porous material [56]. However, the internal resistance of the unstretched latex/SWNTs electrode is $1.8 \Omega$, which increases to $7.5 \Omega$ and $10.8 \Omega$ after 50 and 100 stretches, respectively (Fig. 7a). The internal resistance further increases to $26.9 \Omega$ 
under $100 \%$ strain (Fig. 7b); this again is mostly likely due to the low electrical conductivity on the SWNTs film after repetitive stretching to $100 \%$ strain. The cycling stability of the latex/SWNTs electrodes when subjected to a different number of stretches (Fig. 8a) and applied strain percentages (Fig. 8b) shows typical galvanostatic charge/discharge profiles with a constant current density of $0.25 \mathrm{~mA} / \mathrm{cm}^{2}\left(1 \mathrm{~A} \mathrm{~g}^{-1}\right)$. The charge/discharge curves of the latex/SWNTs electrodes indicate good capacitive behavior even after 50 and 100 stretch cycles and under various levels of strain (Fig. 8a and 8b). The symmetrical shape indicates that highly conductive SWNTs create a pathway for the transfer of ions and electrons, thus decreasing internal resistance. Importantly, it takes 84 seconds for the unstretched latex/SWNTs electrode to reach one charge/discharge cycle, while after 100 stretch cycles the sample shows a less charge/discharge time of $\approx 67$ seconds (Fig. 8a). A longer cycle time indicates a higher amount of charge stored in the capacitor, since this measurement is carried out under constant current.

We have also investigated the cycling stability of the unstretched latex/SWNTs electrode (Fig. 9a) after applying 50 (Fig. 9b) and 100 stretch cycles (Fig. 9c). For these measurements, $1000 \mathrm{CV}$ cycles are performed and the $1^{\text {st }}$ cycle, $500^{\text {th }}$ cycle and $1000^{\text {th }}$ cycle are shown in Fig 9. The CV curves show a slightly decreased current after stretching the electrode 50 times, with a further decrease in current after stretching 100 times. This effect indicates that the internal resistance of the electrode inhibits the charge collection and the lower conductivity of the $1 \mathrm{M} \mathrm{Na}_{2} \mathrm{SO}_{4}$ electrolyte also limits diffusion of $\mathrm{Na}^{+}$ions into the nanotube film [57]. However, $\approx 55 \%$ of the initial capacitance remains after the $100^{\text {th }}$ stretching cycle of the electrode during the $1000^{\text {th }} \mathrm{CV}$ cycle at $100 \mathrm{mV} \mathrm{s}^{-1}$ scan rate (Fig. 9d). In addition, there is a consistent decrease in the current and capacitance as a function of the number of stretches and CV cycle. This behavior can be explained by the initial charge formed by the ion adsorption at the same scan rates. Furthermore, the cracks on the SWNTs 
film observed after 50 and 100 stretches could be attributed to irreversible loss of electrons between the surface of the electrode and electrolyte, thus causing degradation of the substrate [57].

\section{Conclusion}

SWNTs were characterized using FT-IR and Raman spectroscopy. Three significant peaks on the FT-IR spectroscopy at $1581 \mathrm{~cm}^{-1}, 1736 \mathrm{~cm}^{-1}$ and $3428 \mathrm{~cm}^{-1}$ were observed, corresponding to the carbonyl groups stretch of the carboxylate anions and carboxylic acid groups, respectively. In addition, Raman spectroscopy showed that the level of defects on the SWNTs increased after functionalization.

The latex/SWNTs electrode was successfully fabricated using a spray coating method. Using cyclic voltammetry the latex/SWNTs electrode displayed typical capacitive behavior under various strains even after repetitive stretching to $100 \%$. The highest capacitance value obtained for the unstretched SWNTs electrode was $119 \mathrm{Fg}^{-1}$ in $1 \mathrm{M} \mathrm{Na}_{2} \mathrm{SO}_{4}$ at $5 \mathrm{mVs}^{-1}$. However, the electrochemical performance of the latex/SWNTs electrode decreased with an increase in the number of stretches and the degree of strain. Approximately $80 \%$ of the initial capacitance remained after 100 stretch cycles. The high surface area, high stability and stretchability of the latex/SWNTs electrode demonstrate that this kind of carbon nanotube film has potential advantages for wearable and biocompatible devices.

\section{Acknowledgment}

We gratefully acknowledge the Australian Research Council (ARC) for funding support. The authors acknowledge use of the facilities and the assistance of Dr. Patricia Hayes, Adrian

Gestos and Tony Romeo at the UOW Electron Microscopy Centre and the Australian National Fabrication Facility (ANFF) for supporting the equipment and research. 


\section{References}

[1] Y. Sun, J.A. Rogers, Inorganic Semiconductors for Flexible Electronics, Advanced Materials, 19 (2007) 1897-1916.

[2] V.L. Pushparaj, M.M. Shaijumon, A. Kumar, S. Murugesan, L. Ci, R. Vajtai, R.J. Linhardt, O. Nalamasu, P.M. Ajayan, Flexible energy storage devices based on nanocomposite paper, Proceedings of the National Academy of Sciences, 104 (2007) 1357413577.

[3] K. Jain, M. Klosner, M. Zemel, S. Raghunandan, Flexible Electronics and Displays: HighResolution, Roll-to-Roll, Projection Lithography and Photoablation Processing Technologies for High-Throughput Production, Proceedings of the IEEE, 93 (2005) 1500-1510.

[4] Y.-k. Zhou, B.-l. He, W.-j. Zhou, H.-l. Li, Preparation and Electrochemistry of SWNT/PANI Composite Films for Electrochemical Capacitors, Journal of The Electrochemical Society, 151 (2004) A1052-A1057.

[5] S.W. Lee, J. Kim, S. Chen, P.T. Hammond, Y. Shao-Horn, Carbon Nanotube/Manganese Oxide Ultrathin Film Electrodes for Electrochemical Capacitors, ACS Nano, 4 (2010) 38893896.

[6] D.-Y. Khang, H. Jiang, Y. Huang, J.A. Rogers, A Stretchable Form of Single-Crystal Silicon for High-Performance Electronics on Rubber Substrates, Science, 311 (2006) 208212.

[7] Y. Sun, W.M. Choi, H. Jiang, Y.Y. Huang, J.A. Rogers, Controlled buckling of semiconductor nanoribbons for stretchable electronics, Nature Nanotechnology, 1 (2006) 201207.

[8] D.-H. Kim, J.-H. Ahn, W.M. Choi, H.-S. Kim, T.-H. Kim, J. Song, Y.Y. Huang, Z. Liu, C. Lu, J.A. Rogers, Stretchable and Foldable Silicon Integrated Circuits, Science, 320 (2008) 507-511.

[9] H.C. Ko, M.P. Stoykovich, J. Song, V. Malyarchuk, W.M. Choi, C.-J. Yu, J.B. Geddes, III, J. Xiao, S. Wang, Y. Huang, J.A. Rogers, A hemispherical electronic eye camera based on compressible silicon optoelectronics, Nature, 454 (2008) 748-753.

[10] C. Wang, W. Zheng, Z. Yue, C.O. Too, G.G. Wallace, Buckled, Stretchable Polypyrrole Electrodes for Battery Applications, Advanced Materials, 23 (2011) 3580-3584.

[11] C. Yu, C. Masarapu, J. Rong, B. Wei, H. Jiang, Stretchable Supercapacitors Based on Buckled Single-Walled Carbon-Nanotube Macrofilms, Advanced Materials, 21 (2009) 47934797.

[12] K. Subramaniam, A. Das, G. Heinrich, Development of conducting polychloroprene rubber using imidazolium based ionic liquid modified multi-walled carbon nanotubes, Composites Science and Technology, 71 (2011) 1441-1449.

[13] T.A. Kim, H.S. Kim, S.S. Lee, M. Park, Single-walled carbon nanotube/silicone rubber composites for compliant electrodes, Carbon, 50 (2012) 444-449. 
[14] Y. Zhang, C.J. Sheehan, J. Zhai, G. Zou, H. Luo, J. Xiong, Y.T. Zhu, Q.X. Jia, PolymerEmbedded Carbon Nanotube Ribbons for Stretchable Conductors, Advanced Materials, 22 (2010) 3027-3031.

[15] M.S. Cho, H.J. Seo, J.D. Nam, H.R. Choi, J.C. Koo, K.G. Song, Y. Lee, A solid state actuator based on the PEDOT/NBR system, Sensors and Actuators B: Chemical, 119 (2006) 621-624.

[16] S.J. Kwon, T.Y. Kim, B.S. Lee, T.H. Lee, J.E. Kim, K.S. Suh, Elastomeric conducting polymer nano-composites derived from ionic liquid polymer stabilized-poly(3,4ethylenedioxythiophene), Synthetic Metals, 160 (2010) 1092-1096.

[17] C. Yuan, L. Hou, D. Li, L. Shen, F. Zhang, X. Zhang, Synthesis of flexible and porous cobalt hydroxide/conductive cotton textile sheet and its application in electrochemical capacitors, Electrochimica Acta, 56 (2011) 6683-6687.

[18] A. Kros, S.W.F.M. van Hövel, R.J.M. Nolte, N.A.J.M. Sommerdijk, A printable glucose sensor based on a poly(pyrrole)-latex hybrid material, Sensors and Actuators B: Chemical, 80 (2001) 229-233.

[19] P. Jung Woo, Y. Jung-Hoon, K. Hanseup, A large-deflection high-force micro electromagnetic hydraulic Latex membrane actuator for fluid manipulation in micro channels, Micro Electro Mechanical Systems (MEMS), 2011 IEEE 24th International Conference on, 2011, pp. 1209-1212.

[20] Ş. Uğur, Ö. Yargi, Ö. Pekcan, Conductivity percolation of carbon nanotubes (CNT) in polystyrene (PS) latex film, Canadian Journal of Chemistry, 88 (2010) 267-276.

[21] Z. Spitalsky, D. Tasis, K. Papagelis, C. Galiotis, Carbon nanotube-polymer composites: Chemistry, processing, mechanical and electrical properties, Progress in Polymer Science, 35 (2010) 357-401.

[22] L. Hu, W. Yuan, P. Brochu, G. Gruner, Q. Pei, Highly stretchable, conductive, and transparent nanotube thin films, Applied Physics Letters, 94 (2009) -.

[23] X. Wang, P.D. Bradford, W. Liu, H. Zhao, Y. Inoue, J.-P. Maria, Q. Li, F.-G. Yuan, Y. Zhu, Mechanical and electrical property improvement in CNT/Nylon composites through drawing and stretching, Composites Science and Technology, 71 (2011) 1677-1683.

[24] J. Shen, A. Liu, Y. Tu, G. Foo, C. Yeo, M.B. Chan-Park, R. Jiang, Y. Chen, How carboxylic groups improve the performance of single-walled carbon nanotube electrochemical capacitors?, Energy \& Environmental Science, 4 (2011) 4220-4229.

[25] Y.-T. Kim, Y. Ito, K. Tadai, T. Mitani, U.-S. Kim, H.-S. Kim, B.-W. Cho, Drastic change of electric double layer capacitance by surface functionalization of carbon nanotubes, Applied Physics Letters, 87 (2005) -.

[26] M.D. Obradović, G.D. Vuković, S.I. Stevanović, V.V. Panić, P.S. Uskoković, A. Kowal, S.L. Gojković, A comparative study of the electrochemical properties of carbon nanotubes and carbon black, Journal of Electroanalytical Chemistry, 634 (2009) 22-30. 
[27] R.Z. Ma, J. Liang, B.Q. Wei, B. Zhang, C.L. Xu, D.H. Wu, Study of electrochemical capacitors utilizing carbon nanotube electrodes, Journal of Power Sources, 84 (1999) 126129.

[28] E. Frackowiak, K. Metenier, V. Bertagna, F. Beguin, Supercapacitor electrodes from multiwalled carbon nanotubes, Applied Physics Letters, 77 (2000) 2421-2423.

[29] E. Frackowiak, K. Jurewicz, S. Delpeux, F. Béguin, Nanotubular materials for supercapacitors, Journal of Power Sources, 97-98 (2001) 822-825.

[30] F. Picó, J.M. Rojo, M.L. Sanjuán, A. Ansón, A.M. Benito, M.A. Callejas, W.K. Maser, M.T. Martínez, Single-Walled Carbon Nanotubes as Electrodes in Supercapacitors, Journal of The Electrochemical Society, 151 (2004) A831-A837.

[31] H. Pan, C.K. Poh, Y.P. Feng, J. Lin, Supercapacitor Electrodes from Tubes-in-Tube Carbon Nanostructures, Chemistry of Materials, 19 (2007) 6120-6125.

[32] C. Liu, F. Li, L.-P. Ma, H.-M. Cheng, Advanced Materials for Energy Storage, Advanced Materials, 22 (2010) E28-E62.

[33] K.H. An, W.S. Kim, Y.S. Park, Y.C. Choi, S.M. Lee, D.C. Chung, D.J. Bae, S.C. Lim, Y.H. Lee, Supercapacitors Using Single-Walled Carbon Nanotube Electrodes, Advanced Materials, 13 (2001) 497-500.

[34] K.H. An, W.S. Kim, Y.S. Park, J.M. Moon, D.J. Bae, S.C. Lim, Y.S. Lee, Y.H. Lee, Electrochemical Properties of High-Power Supercapacitors Using Single-Walled Carbon Nanotube Electrodes, Advanced Functional Materials, 11 (2001) 387-392.

[35] Z. Wu, Z. Chen, X. Du, J.M. Logan, J. Sippel, M. Nikolou, K. Kamaras, J.R. Reynolds, D.B. Tanner, A.F. Hebard, A.G. Rinzler, Transparent, Conductive Carbon Nanotube Films, Science, 305 (2004) 1273-1276.

[36] A.A. Green, M.C. Hersam, Colored Semitransparent Conductive Coatings Consisting of Monodisperse Metallic Single-Walled Carbon Nanotubes, Nano Letters, 8 (2008) 1417-1422.

[37] M.H. Kim, J.Y. Choi, H.K. Choi, S.M. Yoon, O.O. Park, D.K. Yi, S.J. Choi, H.J. Shin, Carbon Nanotube Network Structuring Using Two-Dimensional Colloidal Crystal Templates, Advanced Materials, 20 (2008) 457-461.

[38] M.H.A. Ng, L.T. Hartadi, H. Tan, C.H.P. Poa, Efficient coating of transparent and conductive carbon nanotube thin films on plastic substrates, Nanotechnology, 19 (2008) 205703.

[39] K. Kordás, T. Mustonen, G. Tóth, H. Jantunen, M. Lajunen, C. Soldano, S. Talapatra, S. Kar, R. Vajtai, P.M. Ajayan, Inkjet Printing of Electrically Conductive Patterns of Carbon Nanotubes, Small, 2 (2006) 1021-1025.

[40] J.H. Kim, K.-W. Nam, S.B. Ma, K.B. Kim, Fabrication and electrochemical properties of carbon nanotube film electrodes, Carbon, 44 (2006) 1963-1968. 
[41] J.-Y. Kim, C.S. Lee, J.H. Han, J.W. Cho, J. Bae, Supercapacitors Using Gel Electrolytes and Thin Multiwalled Carbon Nanotube Films Spray-Deposited on ITO Substrates, Electrochemical and Solid-State Letters, 14 (2011) A56-A59.

[42] A.P. Schuetze, W. Lewis, C. Brown, W.J. Geerts, A laboratory on the four-point probe technique, American Journal of Physics, 72 (2004) 149-153.

[43] H.J. Park, M. Park, J.Y. Chang, H. Lee, The effect of pre-treatment methods on morphology and size distribution of multi-walled carbon nanotubes, Nanotechnology, 19 (2008) 335702.

[44] W. Chidawanyika, T. Nyokong, Characterization of amine-functionalized single-walled carbon nanotube-low symmetry phthalocyanine conjugates, Carbon, 48 (2010) 2831-2838.

[45] M.N. Tchoul, W.T. Ford, G. Lolli, D.E. Resasco, S. Arepalli, Effect of Mild Nitric Acid Oxidation on Dispersability, Size, and Structure of Single-Walled Carbon Nanotubes, Chemistry of Materials, 19 (2007) 5765-5772.

[46] H.-Z. Geng, K.K. Kim, K.P. So, Y.S. Lee, Y. Chang, Y.H. Lee, Effect of Acid Treatment on Carbon Nanotube-Based Flexible Transparent Conducting Films, Journal of the American Chemical Society, 129 (2007) 7758-7759.

[47] C. Niu, E.K. Sichel, R. Hoch, D. Moy, H. Tennent, High power electrochemical capacitors based on carbon nanotube electrodes, Applied Physics Letters, 70 (1997) 14801482.

[48] R.K. Saini, I.W. Chiang, H. Peng, R.E. Smalley, W.E. Billups, R.H. Hauge, J.L. Margrave, Covalent Sidewall Functionalization of Single Wall Carbon Nanotubes, Journal of the American Chemical Society, 125 (2003) 3617-3621.

[49] H. Murphy, P. Papakonstantinou, T.I.T. Okpalugo, Raman study of multiwalled carbon nanotubes functionalized with oxygen groups, Journal of Vacuum Science \&amp; Technology B, 24 (2006) 715-720.

[50] Z.-M. Dang, L. Wang, L.-P. Zhang, Surface functionalization of multiwalled carbon nanotube with trifluorophenyl, Journal of Nanomaterials, 2006 (2006).

[51] J.N. Barisci, G.G. Wallace, D. Chattopadhyay, F. Papadimitrakopoulos, R.H. Baughman, Electrochemical Properties of Single-Wall Carbon Nanotube Electrodes, Journal of The Electrochemical Society, 150 (2003) E409-E415.

[52] M.A. Azam, K. Isomura, A. Fujiwara, T. Shimoda, Direct growth of vertically aligned single-walled carbon nanotubes on conducting substrate and its electrochemical performance in ionic liquids, physica status solidi (a), 209 (2012) 2260-2266.

[53] S.R.S. Prabaharan, R. Vimala, Z. Zainal, Nanostructured mesoporous carbon as electrodes for supercapacitors, Journal of Power Sources, 161 (2006) 730-736.

[54] J. Segalini, B. Daffos, P.L. Taberna, Y. Gogotsi, P. Simon, Qualitative Electrochemical Impedance Spectroscopy study of ion transport into sub-nanometer carbon pores in 
Electrochemical Double Layer Capacitor electrodes, Electrochimica Acta, 55 (2010) 74897494.

[55] H. Kurig, A. Jänes, E. Lust, Electrochemical Characteristics of Carbide-Derived Carbon | 1 -Ethyl-3-methylimidazolium Tetrafluoroborate Supercapacitor Cells, Journal of The Electrochemical Society, 157 (2010) A272-A279.

[56] P.L. Taberna, P. Simon, J.F. Fauvarque Electrochemical Characteristics and Impedance Spectroscopy Studies of Carbon-Carbon Supercapacitors, Journal of The Electrochemical Society, 150 (2003) A292-A300.

[57] S. Nataraj, Q. Song, S. Al-Muhtaseb, S. Dutton, Q. Zhang, E. Sivaniah, Thin, flexible supercapacitors made from carbon nanofiber electrodes decorated at room temperature with manganese oxide nanosheets, Journal of Nanomaterials, 2013 (2013). 

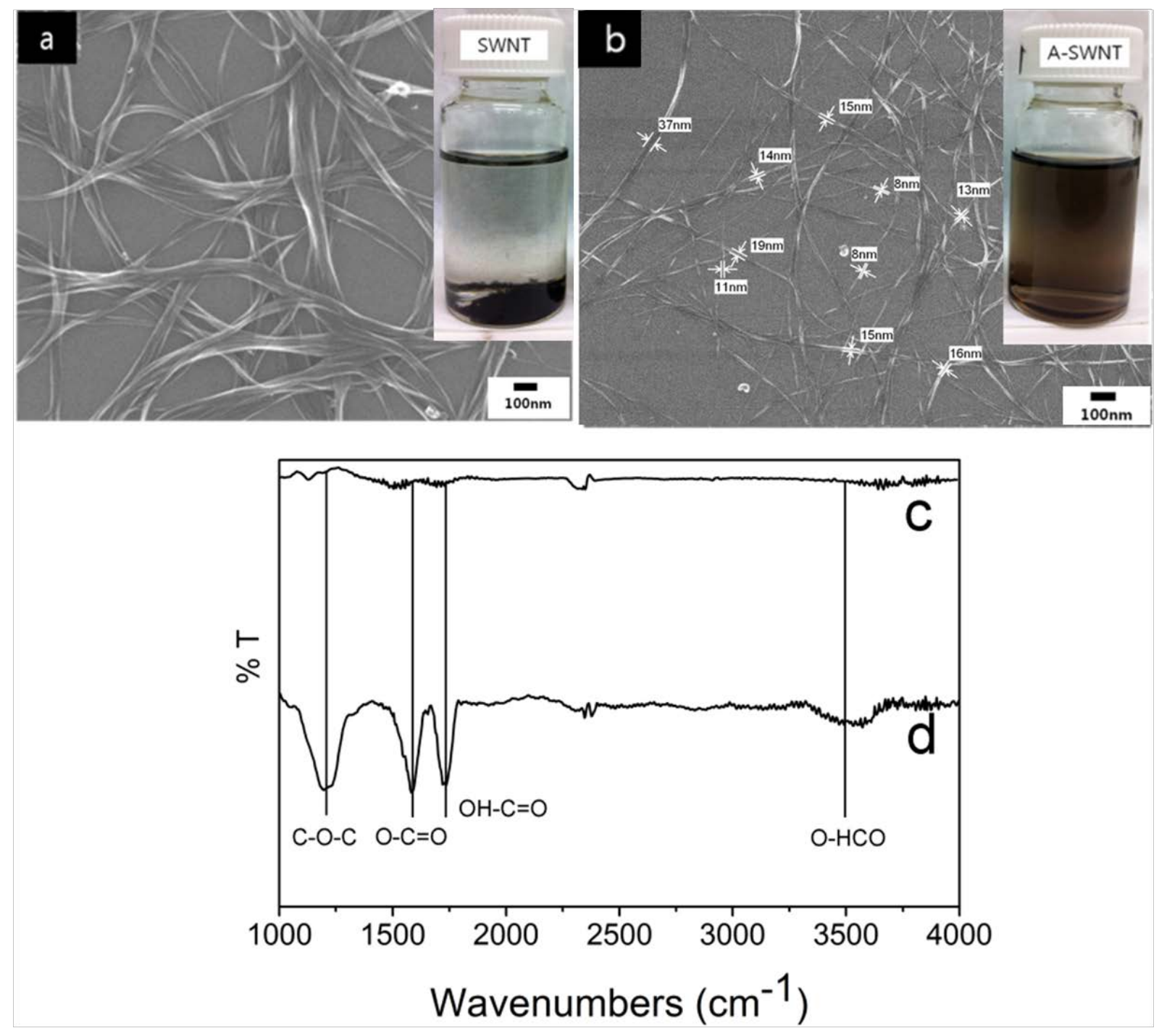

Figure 1 


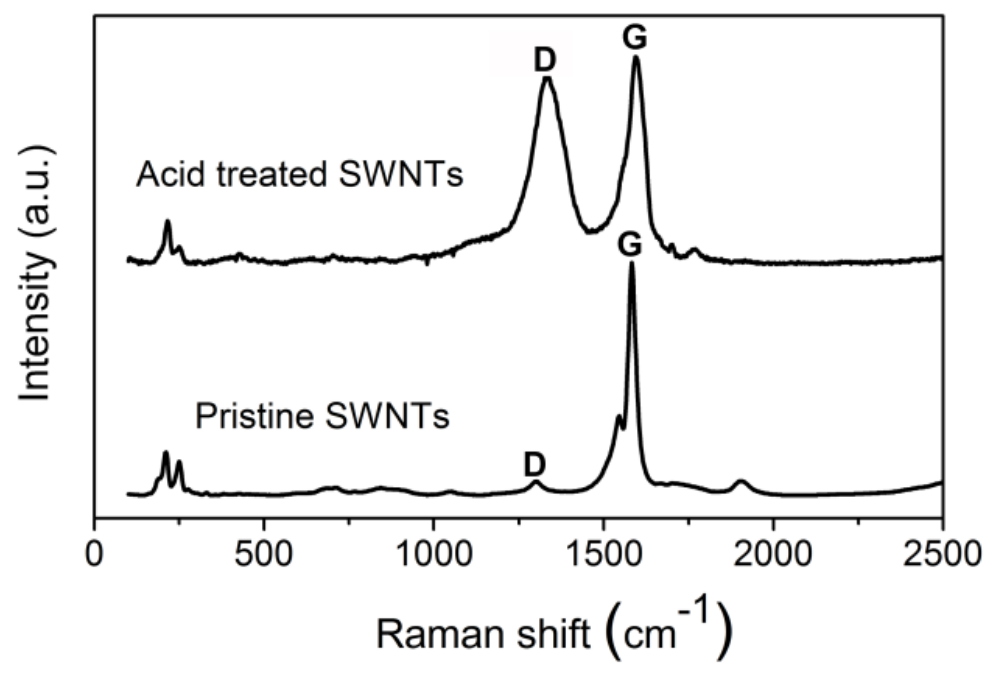

\begin{tabular}{|c|c|c|c|c|}
\hline & $\mathrm{I}_{\mathrm{D}} / \mathrm{I}_{\mathrm{G}}$ & $\mathrm{D}$ band & $\mathrm{G}$ band & diameter $(\mathrm{nm})$ \\
\hline Pristine SWNTs & 0.05 & 1300 & 1583 & $1.17,1$ \\
\hline Acid treated SWNTs & 0.9 & 1336 & 1593 & $1.15,1$ \\
\hline
\end{tabular}

Figure 2 


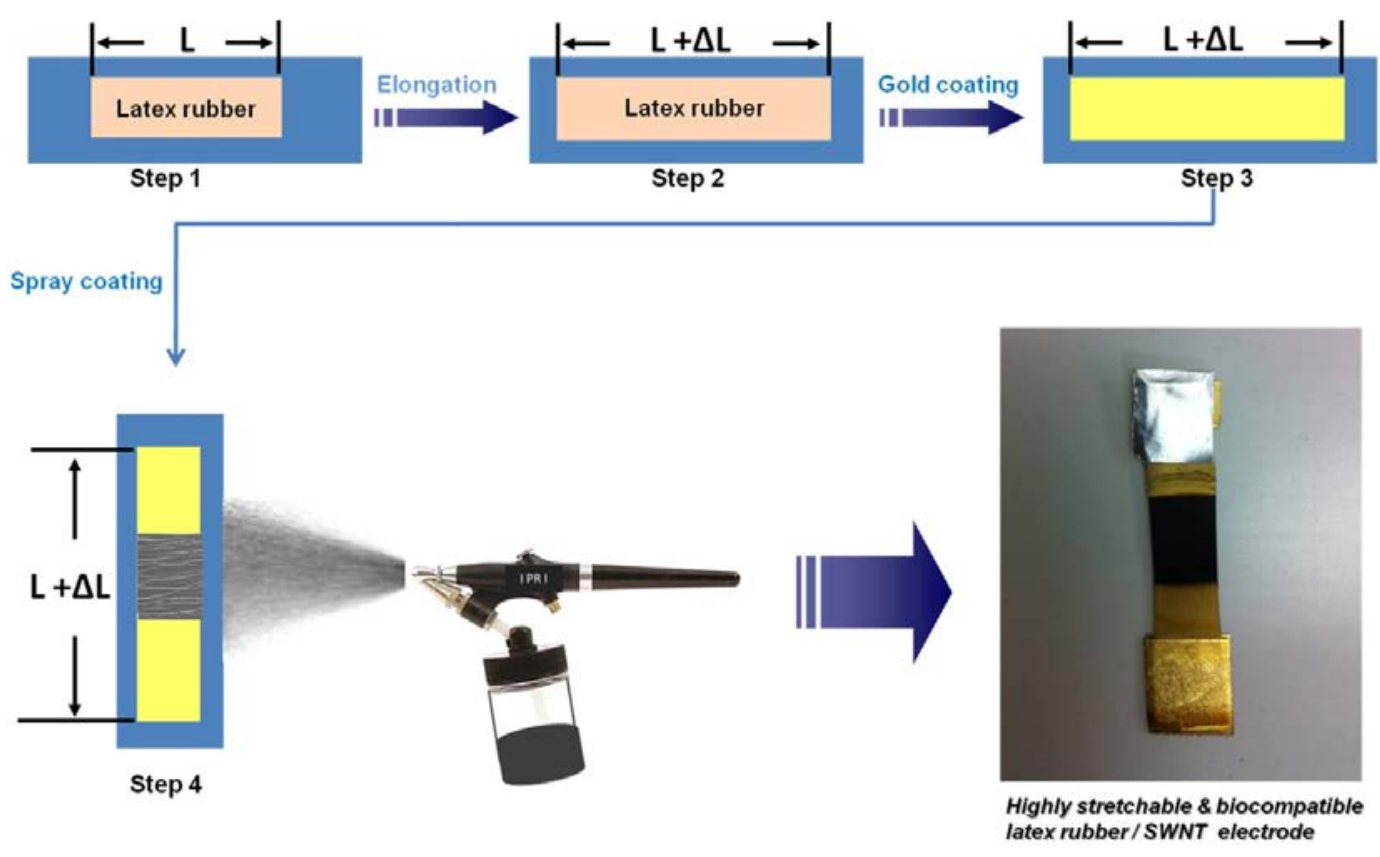

Figure 3 
(a)

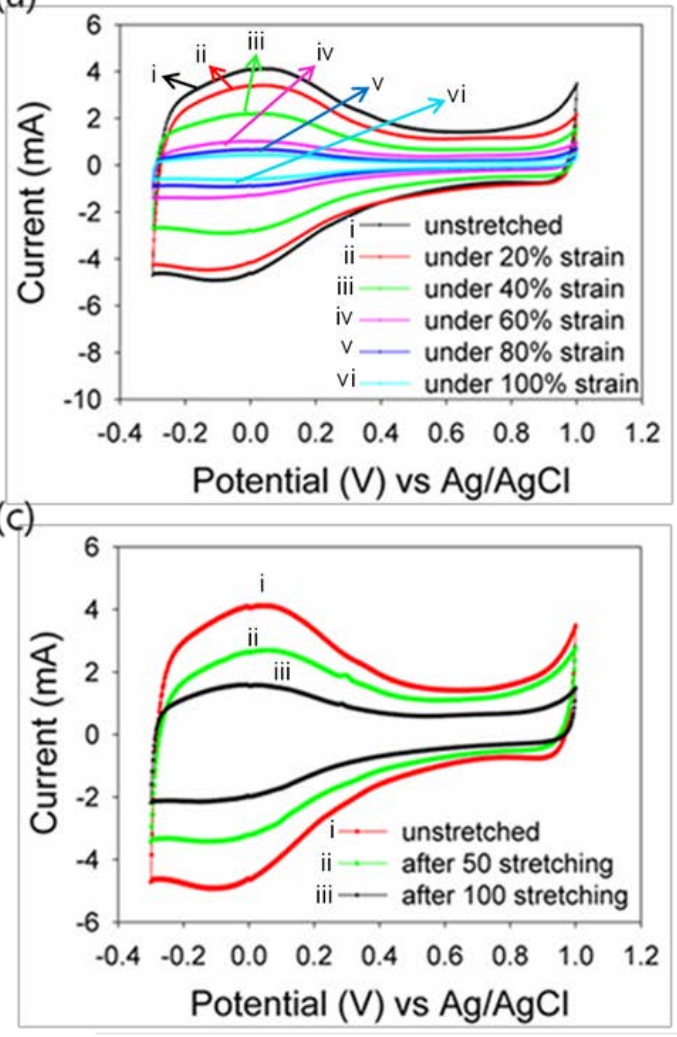

(b)

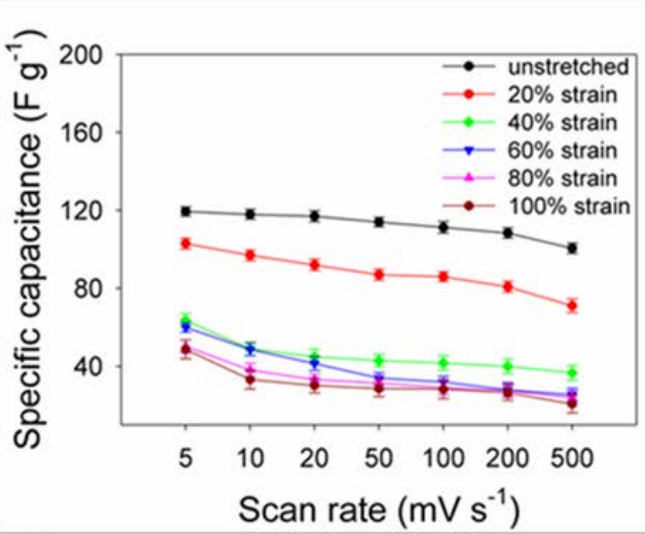

(d)

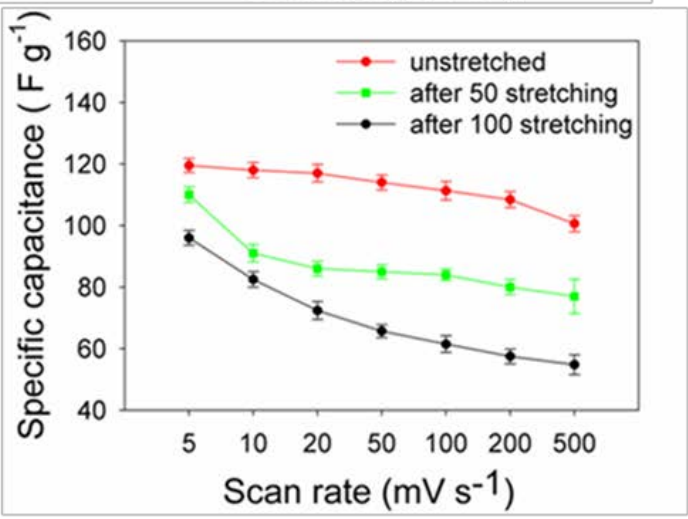

\begin{tabular}{|c|c|c|c|}
\hline & $\begin{array}{c}\text { Specific capacitance } \\
\left(\mathrm{F} \mathrm{g} \mathrm{g}^{-1}\right)\end{array}$ & $\begin{array}{c}\text { Energy Density } \\
\left(\mathrm{Wh} \mathrm{kg}^{-1}\right)\end{array}$ & $\begin{array}{c}\text { Power Density } \\
\left(\mathrm{KW} \mathrm{kg}^{-1}\right)\end{array}$ \\
\hline Unstretched & $100.6( \pm 5)$ & $33.5( \pm 1.6)$ & $50.3( \pm 2.4)$ \\
\hline Under 20\% & $71.1( \pm 3)$ & $23.7( \pm 1)$ & $35.55( \pm 1.5)$ \\
\hline Under 40\% & $36.7( \pm 4)$ & $12.2( \pm 1.3)$ & $18.35( \pm 2)$ \\
\hline Under 60\% & $25.4( \pm 3)$ & $8.46( \pm 1)$ & $12.7( \pm 1.5)$ \\
\hline Under 80\% & $24( \pm 2)$ & $8( \pm 0.6)$ & $12( \pm 0.9)$ \\
\hline Under 100\% & $20.7( \pm 5)$ & $6.9( \pm 1.6)$ & $10.35( \pm 2.4)$ \\
\hline
\end{tabular}

Figure 4 


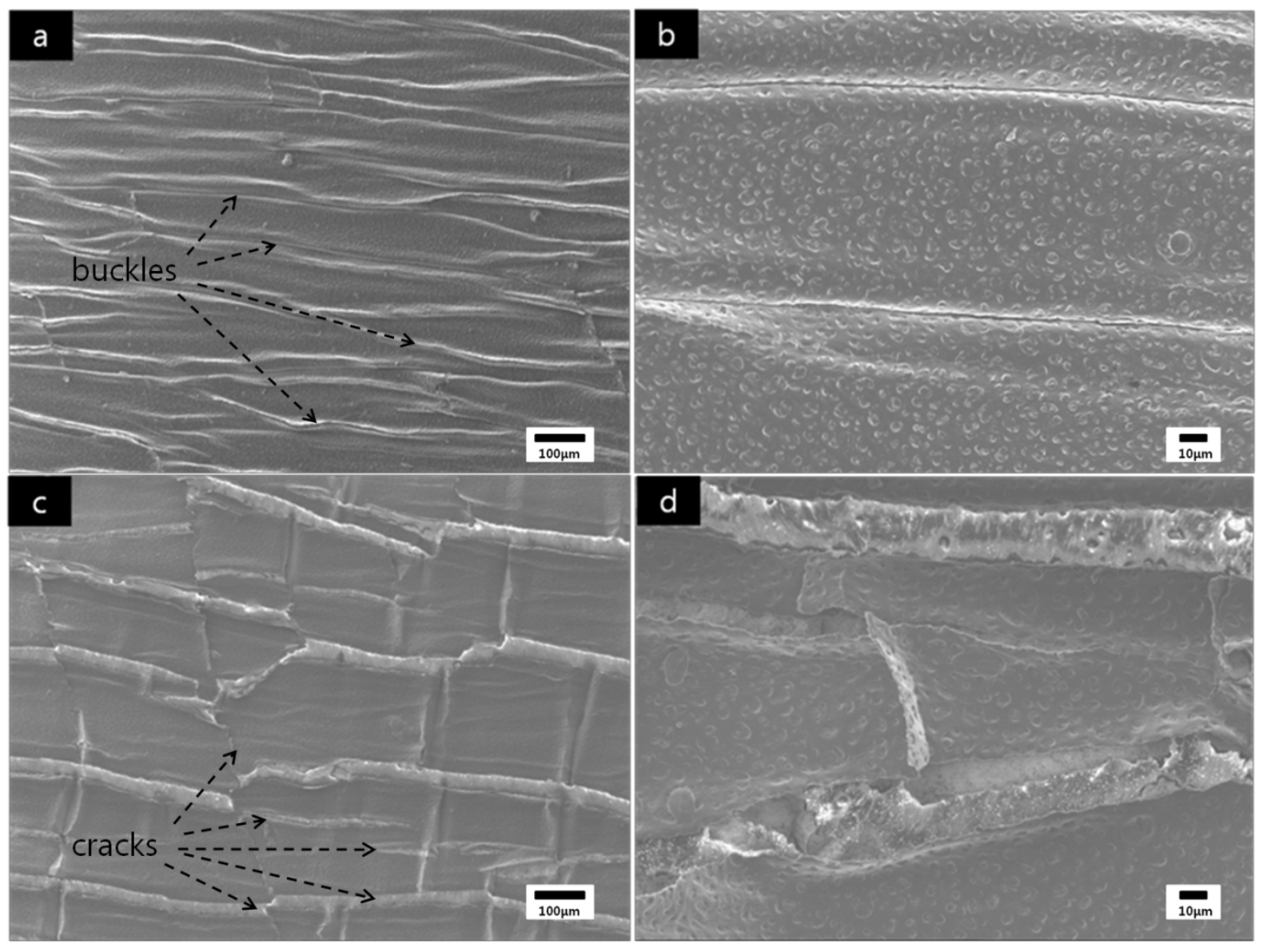

Figure 5 

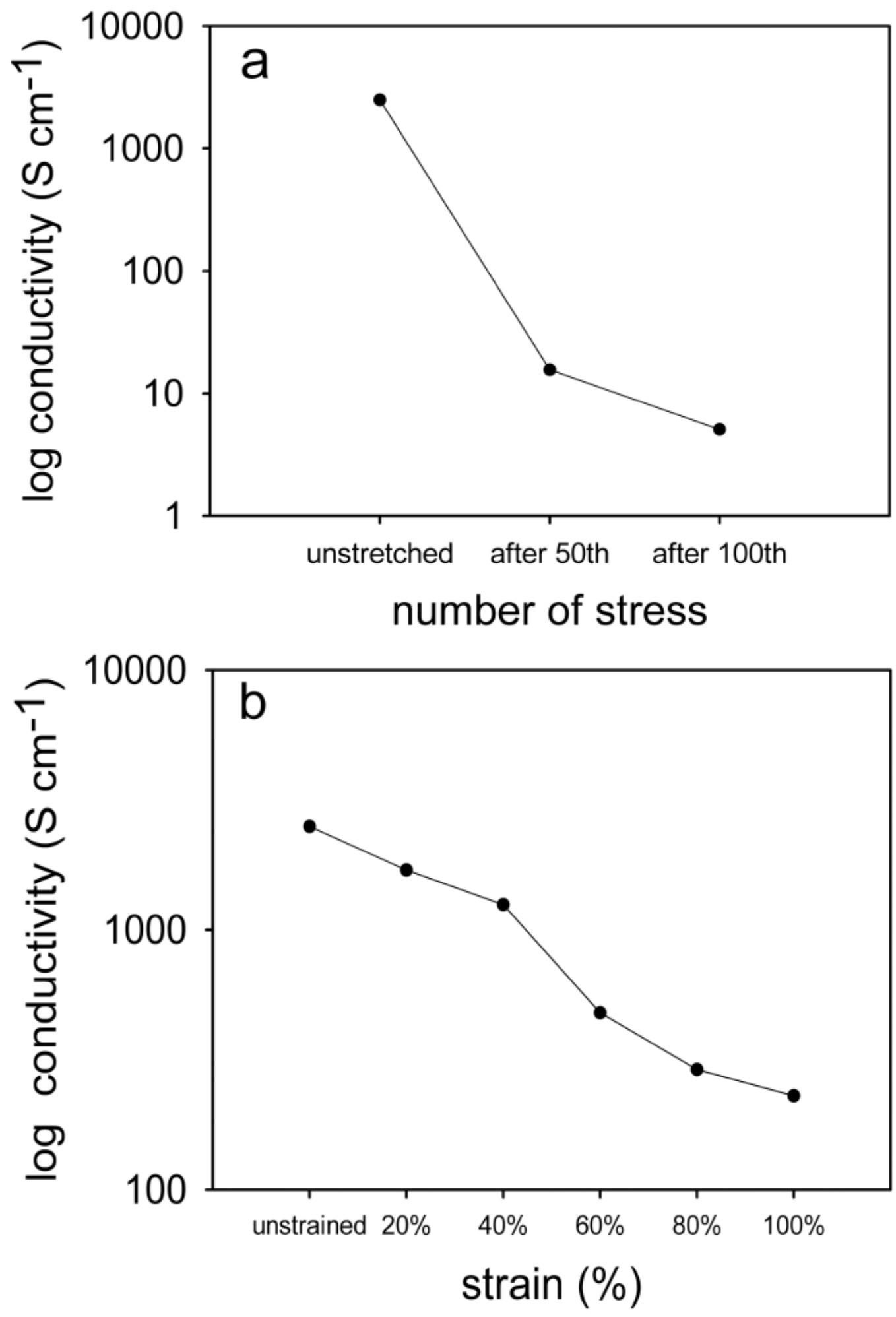

Figure 6 


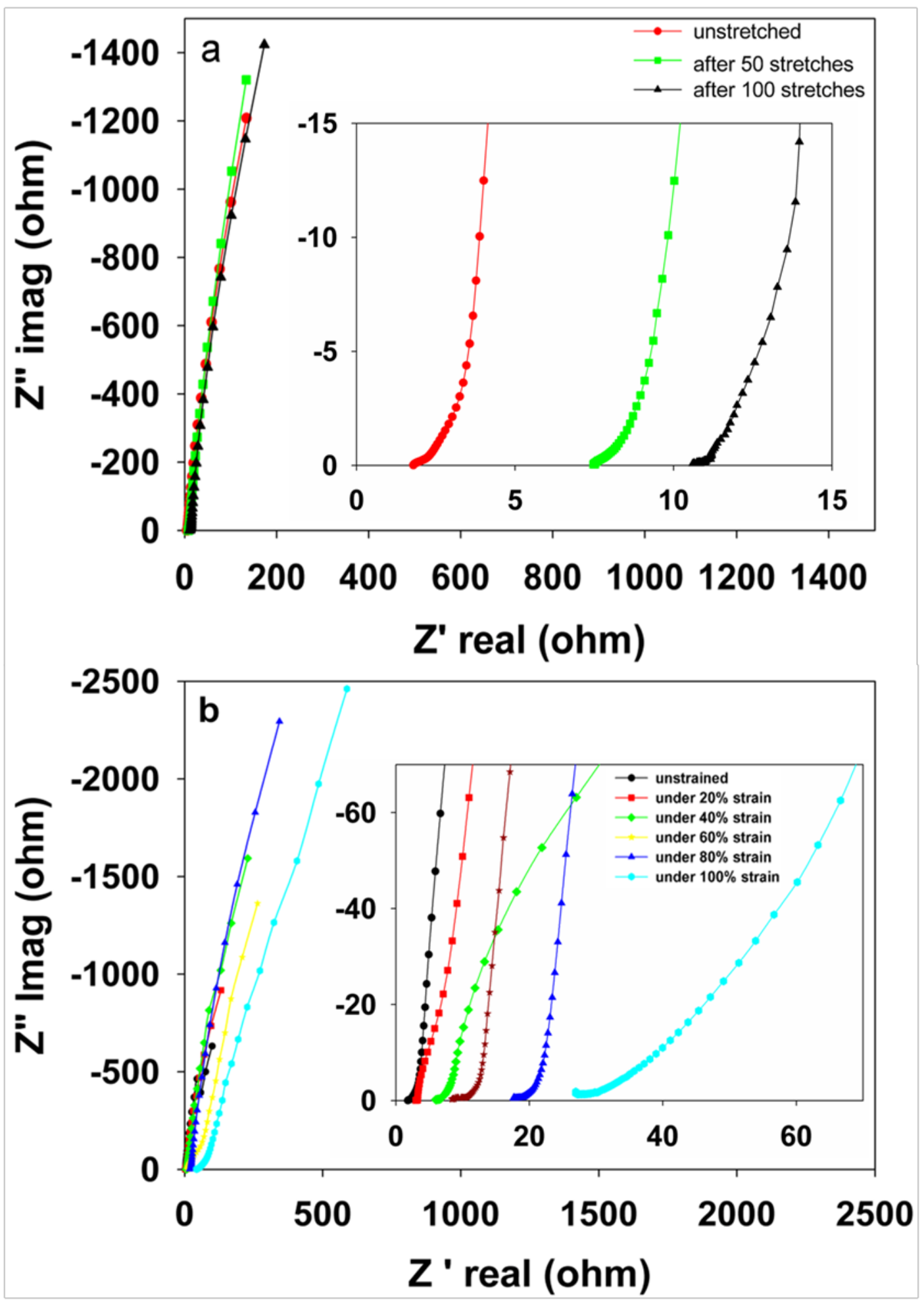

Figure 7 

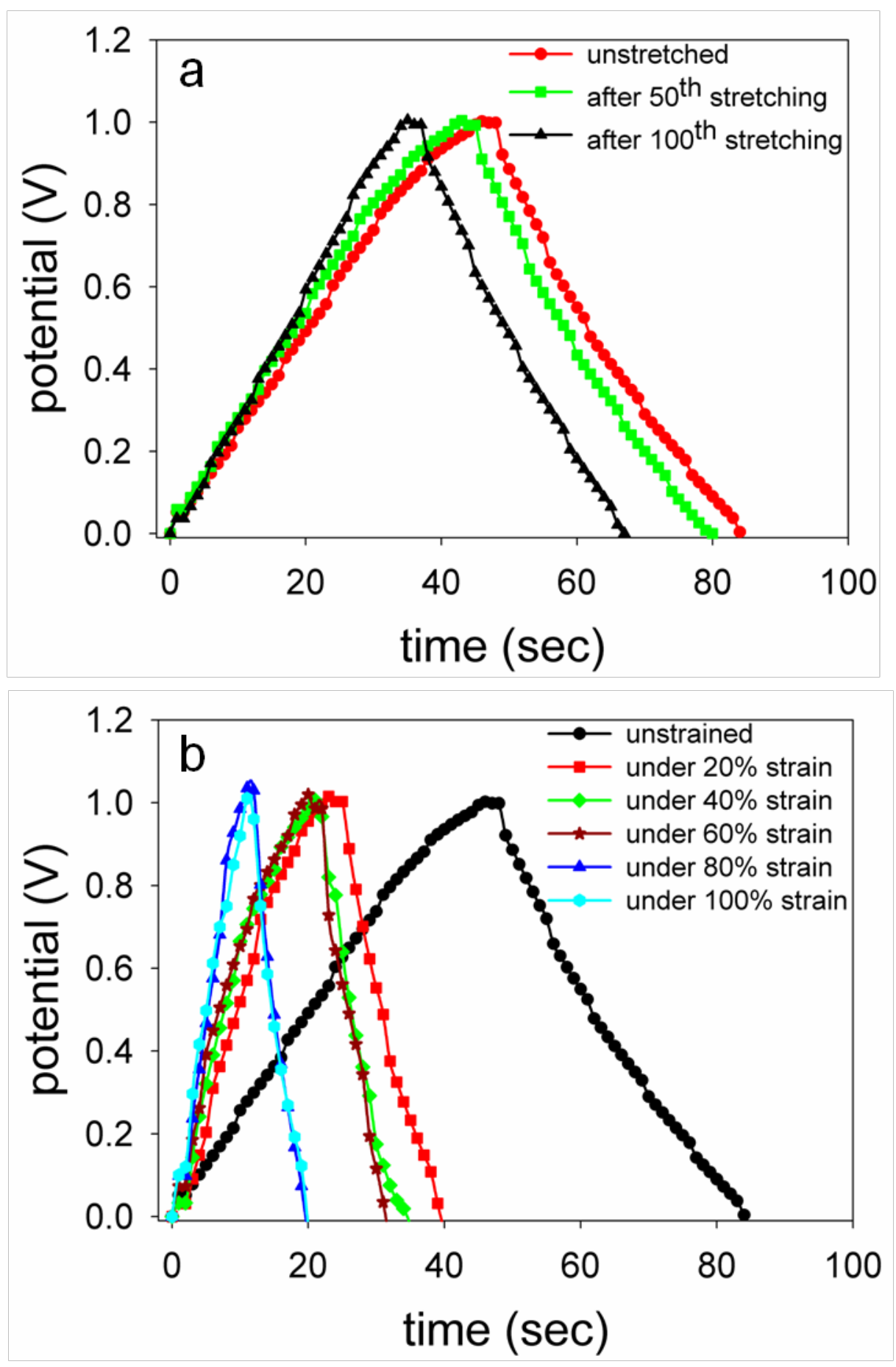

Figure 8 


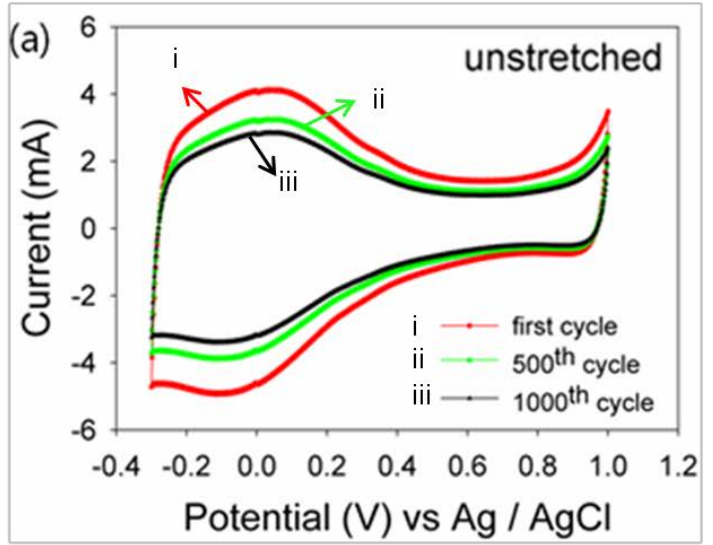

(b)
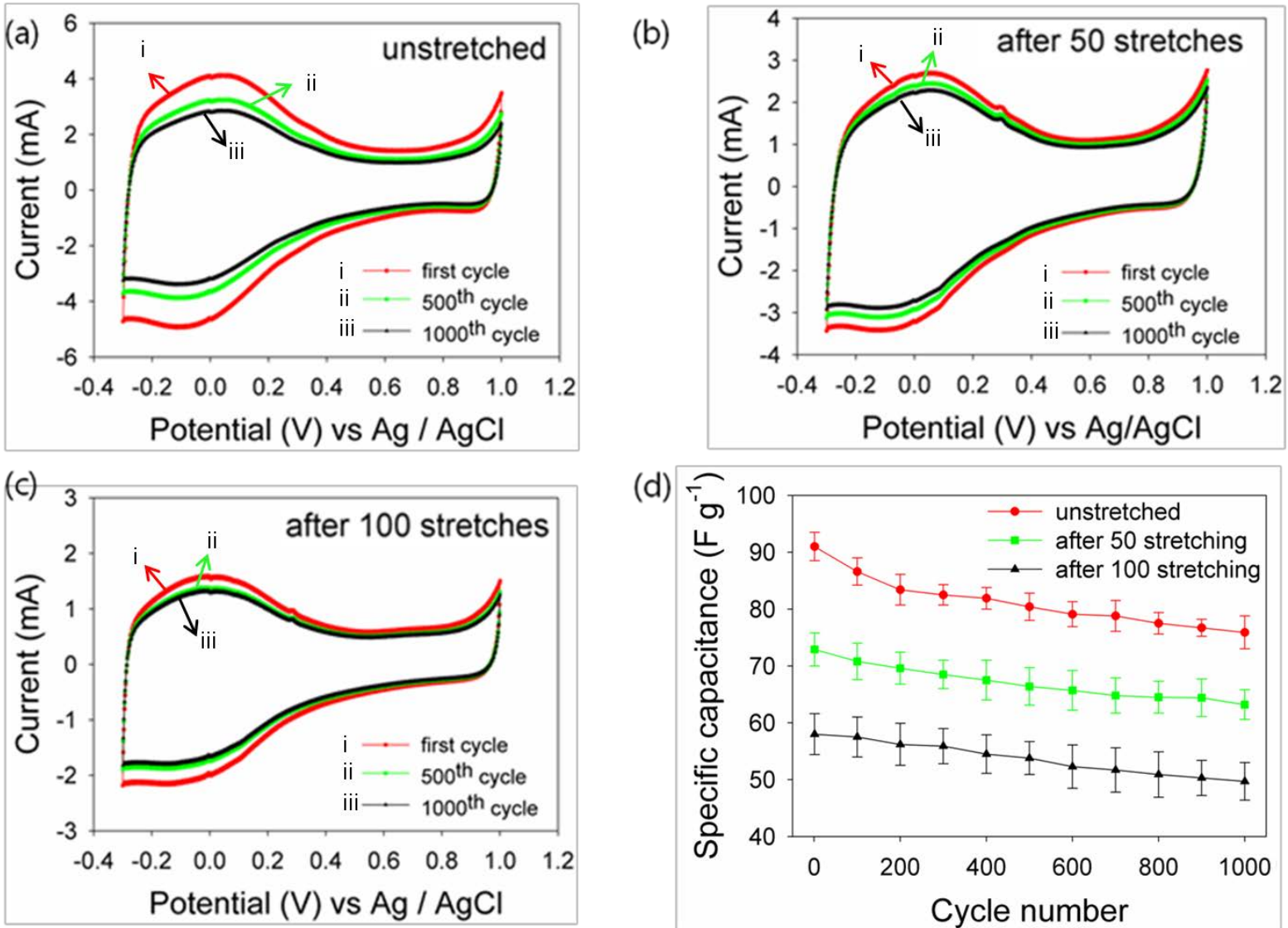

(d)

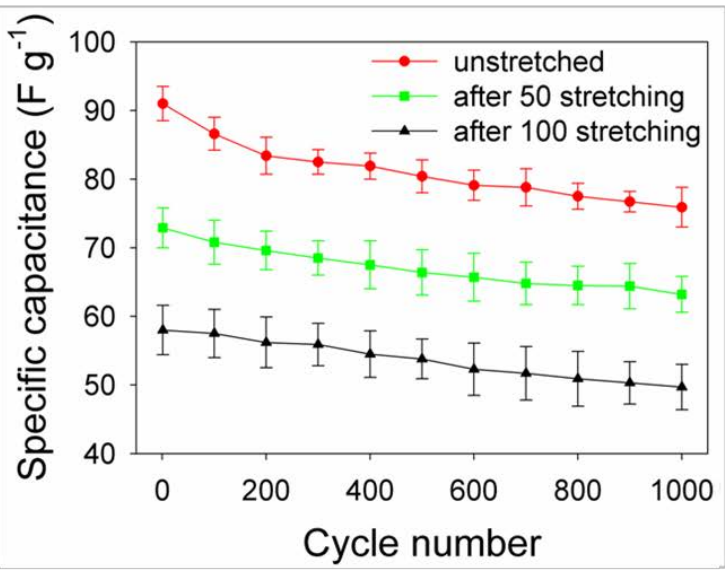

Figure 9 


\section{Captions}

Figure 1: SEM images and FT-IR spectrum of the (a, c) pristine SWNTs and (b, d) functionalized SWNTs.

Figure 2: Raman spectra of the pristine SWNTs and functionalized SWNTs.

Figure 3: Preparation of the stretchable latex/SWNTs electrode via spray coating technique.

Figure 4: Cyclic voltammograms and specific capacitance of latex/SWNTs electrodes at various strain percentages and stretching in $1 \mathrm{M} \mathrm{Na}_{2} \mathrm{SO}_{4}$; (a) under various strain percentage (0 100\% strain with $100 \mathrm{mV} \mathrm{s}^{-1}$ scan rate), (b) specific capacitance under various strain percentage (0 100\% strain with $5 \sim 500 \mathrm{mV} \mathrm{s}^{-1}$ scan rate), (c) after various stretching (0, 50 and 100 times stretching at $100 \%$ strain with 100 $\mathrm{mV} \mathrm{s}^{-1}$ scan rate) , (d) specific capacitance after various stretching (0, 50 and 100 times stretching at $100 \%$ strain with $5 \sim 500 \mathrm{mV} \mathrm{s}^{-1}$ scan rate) errors are standard deviation.

Figure 5: SEM images of latex/SWNTs electrode; (a, b) relaxed from 100\% pre-strain, (c, d) under $100 \%$ tensile strain with application of 100 stretches.

Figure 6: Electrical conductivities of the latex/SWNTs electrode (a) after various stretching (0, 50 and 100 times stretching) and (b) under various strain percentage ( $0 \sim 100 \%$ strain).

Figure 7: Nyquist plots of the latex/SWNTs electrode applied with (a) various stretching (0, 50 and 100 times stretching) and (b) strain percentage (0 100\% strain).

Figure 8: Galvanostatic charge/discharge curves of the latex/SWNTs electrode at constant current $\left(1 \mathrm{~A} \mathrm{~g} \mathrm{~g}^{-1}\right)$ in $1 \mathrm{M} \mathrm{Na}_{2} \mathrm{SO}_{4}$ (a) after various stretching $(0,50$ and 100 times stretching), (b) under various strain percentages (0 100\% strain).

Figure 9: Stability and specific capacitance of the latex/SWNTs at varying cycle number of $\mathrm{CV}$ and stretching in $1 \mathrm{M} \mathrm{Na}_{2} \mathrm{SO}_{4}$ at $100 \mathrm{mV} \mathrm{s}^{-1}$; (a) unstretched, (b) after 50 
stretches, (c) after 100 stretches, (d) specific capacitance as a function of CV cycle number $\left(0 \sim 1000^{\text {th }}\right.$ cycles) errors are standard deviation. 